\title{
Genetic Fingerprinting of Root Knot Nematode as important Pest in EGYPT
}

\author{
SANAA. A. HAROON \\ Fayoum University, Faculty of Agriculture, Plant Protection Department \\ Corresponding author: sanaaharoon1951@gmail.com
}

\begin{abstract}
Root knot nematode is considered as one of the most important nematode all over the world in Egypt it was found out that theses nematode attack the root system of most vegetables, fruits and Feld crops causing significance damages and economic loss .Using the morphological characterization isn't enough for nematode identification to species. So different molecular technology was used to identify different isolated of these nematode for fast and more accurate results. The internal transcript spacer (ITS) and restriction fragment length polymorphism (RFLP) of Ribosomal DNA (rDNA) sequences were used to distinguish between different major species of root knot nematode. DNA fragments containing the internal transcribed spacer (ITS) rDNA were amplified from DNA genome of different Meloidogyne spp. isolates from different governorate in Egypt. Ten females were used to amplify PCR product. When primers 5368 and 5367 were used for amplification of the ITS region, every isolate from the Meloidogyne spp. gave one major product of approximately $760 \mathrm{bp}$.

When ITS regions of all isolates were digested with restriction enzymes, by using RFLP test (Restriction fragment length polymorphisms), the size of the DNA fragment using Hind III was strong band at 560 bp and another weak band at $200 \mathrm{bp}$ that is typical for M. incognita and M. javanica with Hinf I, bands of 440 and 320 pb were obtained while 520, 240 bp bands were cleared when EcoRl are used. Four bands of 220, 200, 180 and $160 \mathrm{bp}$ were obtained when I restriction enzyme was used. In multiplex test, a fragment of $415 \mathrm{bp}$ was obtained when M. incognita was used as template (positive control), that confirming the fact that most nematodes isolates in Egypt are M. incognita
\end{abstract}

Keywords: Meloidogyne, multiplex, PCR, ribosomal DNA, ITS, RFLP, Scar, restriction enzymes.

\section{Introduction}

During the past few years, rapid advances in molecular biology have affected our understanding of plant diseases and revealed many powerful tools that help in many areas of nematology. The new tools include species, race and patliotype identification, development of resistant cultivars, population dynamics, development of useful biological control agents and the design of new nematicides.

This review will highlight the area of biotechnology for the prospects of future advances in applied nematology that is extremely useful nowadays.

In the beginning, it is very important to reach an accurate identification of nematode species, it is the fundamental of nemato-logical research, quarantine enforcement for regulatory purposes and nematode management, especially management that does not rely on nematicides. An immediate objective of new molecular biology techniques in nematology is to increase the accuracy and speed of genus and species identification.

A few years ago, root-knot nematodes (Meloidogyne spp.) are sometimes difficult to be identified using traditional morphological characterization, so alternative identification methods that are easily interpreted are desirable. It is now possible to distinguish among root knot nematodes by the use of DNA markers, the big advantage of using DNA that it does not change with environmental conditions during a nematode's lifetime. Consequently, DNA markers are stable and useful when applied for identifying nematode species and populations. Various DNA polymorphisms that allow identification of the major root-knot nematode species have been described also polymerase chain reaction (PCR) is a recently developed technique that has been of particular consequence to molecular genetics because it allows amplification of specific sequences from minute quantities of DNA. In PCR two oligonucleotide primers are used to hybridize to opposite DNA strands flanking the desired sequence in the target DNA, so that DNA polymerase can create a copy of the intervening target DNA. The exponential amplification mediated by cycles of heating and cooling can produce 106 - 109 copies of the target DNA sequence. The technique is effective with samples containing little biomass; for example, it has been used to amplify DNA from single human sperm or from blood stains.

Restriction fragment length polymorphisms (RFLPs) generated after PCR amplification of ribosomal DNA can be vised for identification of single root-knot nematode 2nd Juvenile J2). The technique uses PCR and primers to generate DNA fragments that are subsequently subjected to restriction endonuclease digestion, yielding speciesspecific RFLPs that allow discrimination of different root knot nematode species such as $M$. arenaria, $M$. chitwoodi, M. incognita, M. javanica, and M. hapla.

Random amplification of polymorphic DNA (RAPD) assaying the entire genome for DNA markers is a powerful way to obtain markers linked to characters of interest. The RAPD assay refers to PCR amplification of target DNA with single primer, and hence produces DNA fragments distributed over the 
entire target DNA pool. Because RAPD analysis uses random primers for PCR, for knowledge of the nucleotide sequence information comprising the nematode genome is not required; because R APD analysis uses PCR technology requires only tiny amounts of DNA and can be applied to single juveniles or single cyst.

The identification of root-knot nematode $\mathrm{J} 2$ is especially valuable, because $\mathrm{J} 2$ are the stage extracted from soil samples but are difficult or impossible to identify the species level with traditional techniques. RAPD analysis has been used to successfully distinguish $M$. arenaria, $M$. incognita, $M$. javanica and $M$. hapla, however, because this technique is sensitive to operate effects that cause variation in banding patterns, identification across different laboratories is difficult. Thus, it is desirable to clone species-specific RAPD markers, sequence the clones, and then synthesize larger, more stable primers that allow reliable amplification of the diagnostic bands.

Genetic variability in nematode populations and their hosts, are just beginning to be documented, because genetic variability among nematodes was not especially important while nematicides were available and more importantly because the tools for assessing genotypic variation have become available only during the past 10 to 20 years. For each nematode species, genetic markers associated with host range or life history characters would be valuable in developing management practices that reduce nematode pathogenicity and fitness by allowing monitoring and selection for specific genotypes.

Variability has been widely recognized in Meloidogyne spp., with morphometric, reproductive, physiological and cytogenetic variants observed on different host plants. Variation in pathoge-nicity and reproduction on 10 different hosts was observed among 12 populations of $\mathrm{M}$. arenaria race.

The next challenge in the application of the new technologies is to obtain DNA polymorphisms useful as markers to identify patho types, races, and geographic isolates of Meloidogyne spp., and several researchers are looking for such markers.

Molecular techniques can be also used for nematode population dynamics and management, several root-knot nematode species occur in the same field. For example, $M$. arenaria, $M$. incognita, often occur together in most fields around the world. Part of the difficulty lies in defining the species that are present and their relative proportions, before and after rotations. Certain hosts in a rotation series will favor increase of one of the root-knot nematodes, and it is difficult to sample such fields accurately with morphology-based nematode identification. So multiplex test can be used to determine the population dynamics of mixed populations in the same field. This technique becomes widely used in routine diagnostic tests to identify species and to sensitivity differentiate them from each other in field population. It depends on the used of four primers in a single PCR reaction, also this test makes it possible to detect species present in mixtures in proportions as low as 2 to $5 \%$.

\section{So the objective of our project is:}

Accurate identification of genes, species and population of Root knot nematode as a major pest in field crops, vegetables and fruits in Egypt by using molecular technology.

\section{Materials and Methods:}

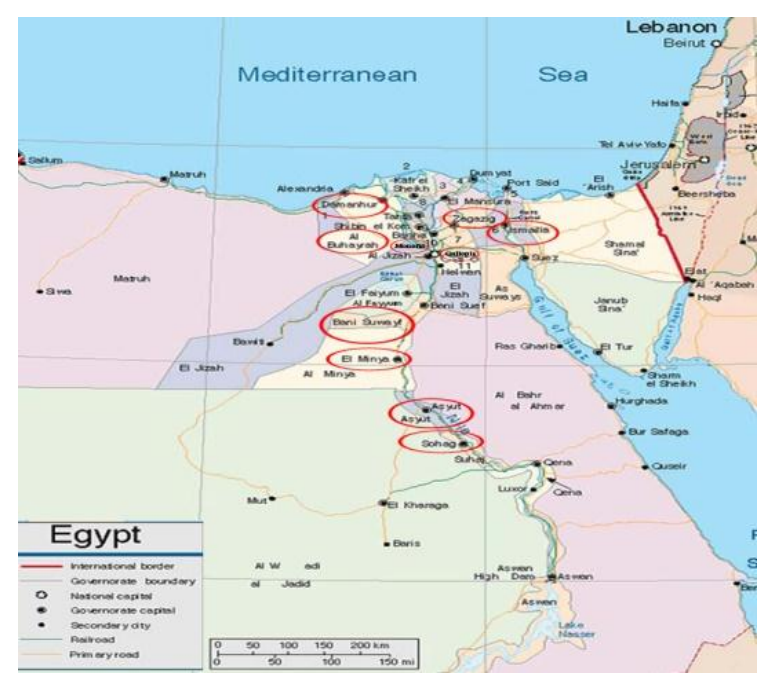

Collection of Nematode Samples: samples were collected from agricultural sectors of different governorates in Egypt fig(1)

Fig (1): The samples were handled with care and stored at $10-15 \mathrm{C}^{0}$ until the analysis in nematology lab (college of agriculture, Fayoum University).

(The survey includes agronomics crops, vegetables, cut flowers and fruit trees. The most common crops were pea, pepper, potato, strawberry, squash, cucumber and tomato, among the vegetable, and cotton, corn, soybean, peanut and sunflower among other crops also banana, peach and grapevine and ornamentals. Table (1)

Nematodes extraction from the soil samples: Nematode was extracted from the soil sample and was recovered according to centrifugal flotation method Jenkins, 1964). Extracted nematodes were identified to the genetic level, and counted under microscope using the Hawksley counting slide.

Root samples were carefully washed with tap water and cut into small pieces in a Petri dish with 10 $\mathrm{ml}$ water. Roots were then teased with dissecting needles to collect mature females necessary for species identification and tissue culture propagation. 
Table (1)

\begin{tabular}{lcc}
\hline \multicolumn{1}{c}{ Governorate } & No. of regions & Major crops in the area \\
\hline Beni Suief & 4 & Tomato, cucumber, lettuce \\
\hline Al Gharbya & 4 & Banana, Grape, Apple, vegetables, Israeli Banana \\
\hline Al Qaliubya & 6 & Tomato, cucumber, squash \\
\hline AL BUHEIRA & 6 & Cucumber, Peach, Tomato, Eggplant, Beans \\
\hline SUHAG & 10 & Grape,Cucumber, Tomato, Banana, Horticultural Crops, banana \\
\hline ASSUIT & 6 & Pomegranate, Banana, Eggplant, Tomato \\
\hline Al Minya & 9 & Okra, Eggplant, banana, tomato \\
\hline Al Sharqya & 7 & Eggplant, Tomato, Cucumber \\
\hline Al Ismailia & 5 & Tomato, Black nightshade \\
\hline Al Monofya & 1 & Grape \\
\hline
\end{tabular}

Preparation of pure culture from root knot nematode samples: One adult female with one egg mass from each sample were propagated in pots filled with sterilized sands under greenhouse condition to insure the purity of the population for each sample that will be used for DNA extraction (fig 2 ). Preparation of root explant cultures was accomplished according to Haroon et al., (1993). Seeds were sinicated for 3 min. in $95 \%$ ethanol followed by a 10-min soak in $0.5 \%$ sodium hypochlorite and were transferred to sterile $1.5 \%$ water agar plates where they were maintained for 3 days at $25^{\circ} \mathrm{C}$. A 5-mm-long root tip was excised from each seed-plate (one root tip per plate) containing Gamborg's B-5 medium (Gibco. Grand Island, N.Y.). Each plate was inoculated with one egg mass that was extracted from one population of each genera of root knot nematode. All the plates were stored in an incubator at $28 \mathrm{C}^{\circ}$ and three months later 25 females from each dish were isolated for DNA extraction(Fig.3)

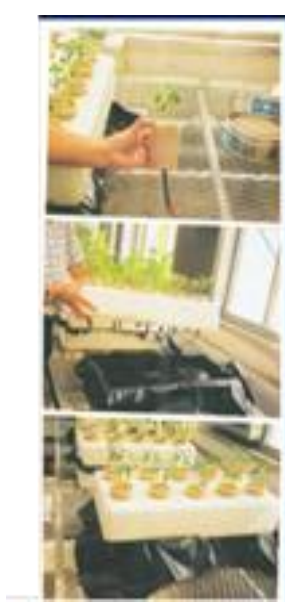

Root knot nematode culture under greenhouse condition

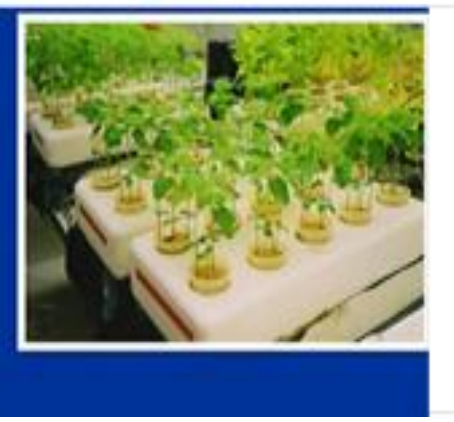

(Fig 2)
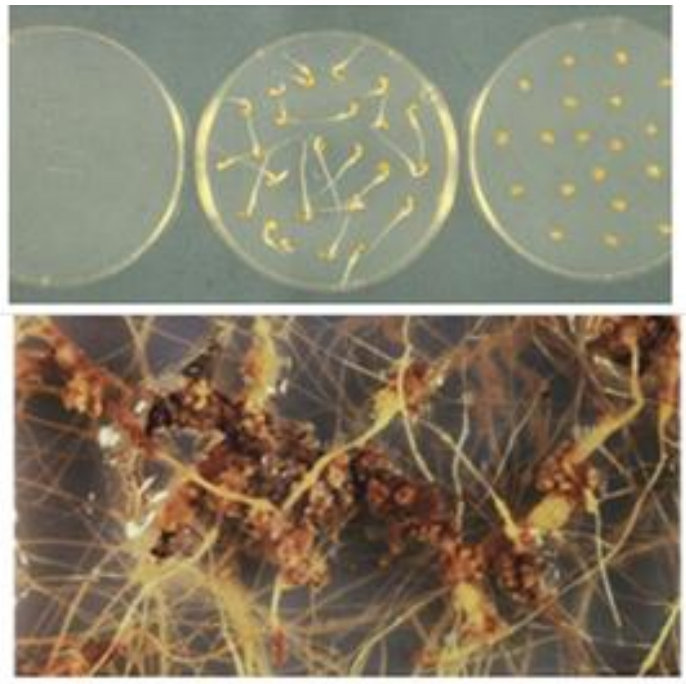

Fig (3): Tomato seeds in water agar and plates after 3 months of inoculation with RKN

FIRST: DNA isolation for Root Knot Nematode molecular identification: DNA

isolated from different samples was done using Genomic prepTM Cells and Tissue DNA Isolation kit (Amersham Pharmacia Biotech, litd, England). Isolated DNA was measured to determine the purity and quality to be used for further experiments as following:

Step 1: Ribosomal DNA amplification (ITS) Primers 5367 (5' - TIGATI

ACGTCCCTGCC CTTT-3') and primer 5368 (5' TTICACTCGCCGTIACAGG3') were sequences as described by Vrain et al.,(1992) and Vrain (1993). The DNA fragments containing the ITS regions were amplified by PCR. The reaction mixtue contained 10 $\underline{\mathrm{mM}}$ Tris, $\mathrm{pH} 9.0 ; 1.5 \mathrm{mM} \mathrm{MgCI} 2 ; 50 \mathrm{mM} \mathrm{KCI} ; 0.01$ $\%$ (wt/vol) gelatin; $0.1 \%$ Trition X-IOO; $100 \mathrm{uM}$ each of dATP dTP dGTP and dTTP (Boehringer GmbH, Mannheim, Germany); 0.6uM each primer; 0.1 to 10 fig of total DNA or the crude DNA extract from 25 females of each isolate; 0.6 units of Taq DNA polymerase (Sphaero Q. Leiden, the Netherlands); and deionized water to a volume of 50 pi. The amplification was carried out in a thermal cycler (PCR) DNA 
Initially PCR amplification conditions were as follows: denaturation at $94^{\circ} \mathrm{C}$ for $2 \mathrm{~min}$, repeated for 20 cycles. A 5-min incubation period at $72 . \mathrm{C}^{\circ}$ followed the last cycle to complete any partially synthesized strands. The fastest available transition between each temperature was used (Zijlestra et al., 1995).

Step 2: ITS-RFLP: Amplified DNA of ITS fragments were digested with Hind I, Hinf I, EcoRI and Dra 1 restriction enzymes. A master mix was prepared by using $1 \mathrm{ul}$ of selected enzyme, $1.5 \mathrm{ul}$ of matching buffer and 12.5 ul of DNA template (obtained from ITS test). The mixture for each sample was placed in incubator at $37^{\circ} \mathrm{C}$ for at least 3 hours or until the second day. The digested DNA was loaded on a $2.5 \%$ agarose gel, separated by electrophoresis and detected by ethidium bromide staining.

Step 3: Species specific (Multiplex) PCR: For conducting the species "'specific (multiplex) PCR test, amplifying segments of the ITS region of each isolate was used. This technique was used to identify root knot nematode species by the size of their amplified fragments in a signal PCR reaction. In other words the test was used for direct identification of the four species based on length polymorphism. The reverse primer HCFI-28S is the backward primer as described by Ferris et al. (1993).

The reaction mixture contained $10 \mathrm{mM}$ Tris $\mathrm{pH}$ 9.0, 3.5mM MgC12, $50 \mathrm{mM} \mathrm{Kcl,} 200$ uMeach of dATP, dCfP, dGTP, and dTTP, $0.4 \mathrm{uM}$ of each forward primers $\mathrm{H}-18 \mathrm{~S}$ (5'CTTGGAGACfGTTGATC3'),CF-ITS (5'-

GATTATACGC ACAATT), and I-ITS ( $\mathrm{S}^{\wedge}$ TGTAGGACTCTTTAATG 3') and $0.4 \mathrm{uM}$ of the reverse primer HCFI-28S. One unit of Taq DNA polymerase (Pharmacia), $3 \mathrm{ng}$ of total DNA or the crude DNA extract from 25 female, was mixed with deionized water to a volume of 50ul. PCR cycle was denaturation at $94 \mathrm{C}^{\circ}$ for $4 \mathrm{~min}$. followed by five cycles at $94 \mathrm{C}^{\circ}$ for $30 \mathrm{~s}, 55 \mathrm{C}^{\circ}$ for $30 \mathrm{~s}, 72 . \mathrm{C}^{\circ}$ for $1 \mathrm{~min}$. with a decrease of $1 \mathrm{C}^{\circ}$ per cycle for the annealing temperature followed by 25 cycles at $94 \mathrm{C}^{\circ}$ for $30 \mathrm{~s}$, $50 \mathrm{C}^{\circ}$ for $30 \mathrm{~s}$, and $72 \mathrm{C}^{\circ}$ for $1 \mathrm{~min}$.

\section{Results:}

Five thousand samples of nematode populations were collected from different agriculture sectors of each governorates that were considered as its important in crop production in Egypt. The survey covers 47 different crops. Results presented show the prominence values of the eleven plant parasitic nematode genera, including ectoparasitic, endoparasitic and semiendoparasitic forms, which were recovered from the soil samples. These genera were Meloidogyne spp., Pratylenclius, Helicotylenclius, Hemicycliophora, Hoplolaimus, Paratylenchus, , Rotylencliulus, Tylenchorhynchus, trichadorus, longidorus, tylenchulus and Xipliinema. The root-knot nematode, Meloidogyne; the lesion nematode, Pratylenclius; the reniform nematode,
Rotylencliulus; the stunt nematode, Tylenchorhynchus and the lance nematode, Hoplolaimus were the major nematodes distributed. Data revealed that Meloidogyne, Pratylenclius and Rotylencliulus were found with relatively higher frequency of occurrence (fig 4), (fig 5), (fig 6A\&B)

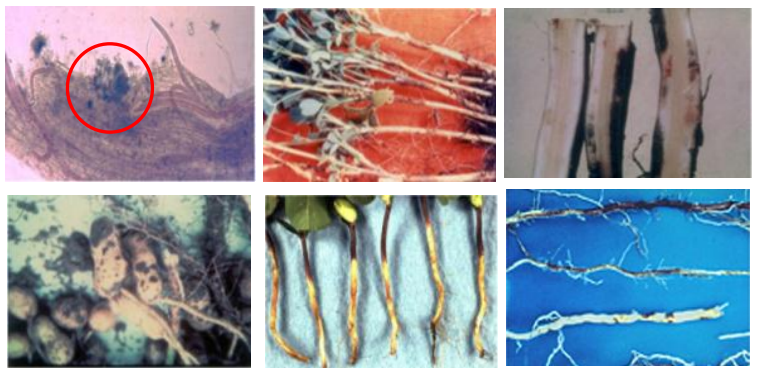

Fig (4) : lesion nematode in clover, Banana, Peanut, strawberry and roses respectively
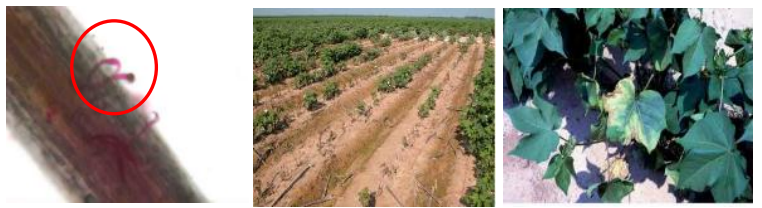

Fig (5) : cotton Nematode in cotton plants

It was very important to identify all the isolated of Root Knot Nematode, to species, races and population as we found out that the majority of crop s is seriously damaged with this group of nematodes, so using this molecular techniques is important to design effective and suitable program of IPM for control this pest

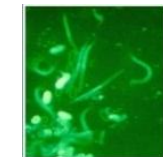

1

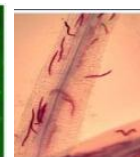

2

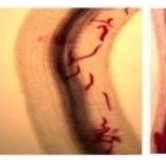

3

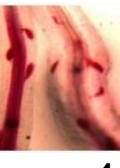

4

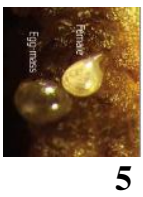

Fig (6 A): Development of Root knot nematode

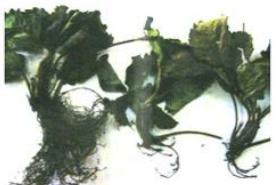

Strawberry

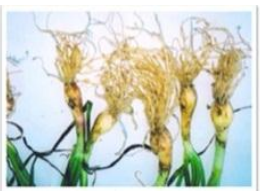

Onion

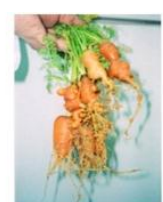

Carrot

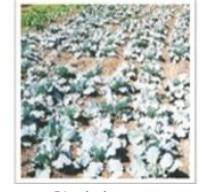

Cabbage

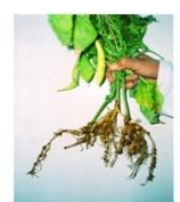

Bean

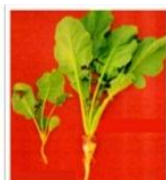

Turnip 

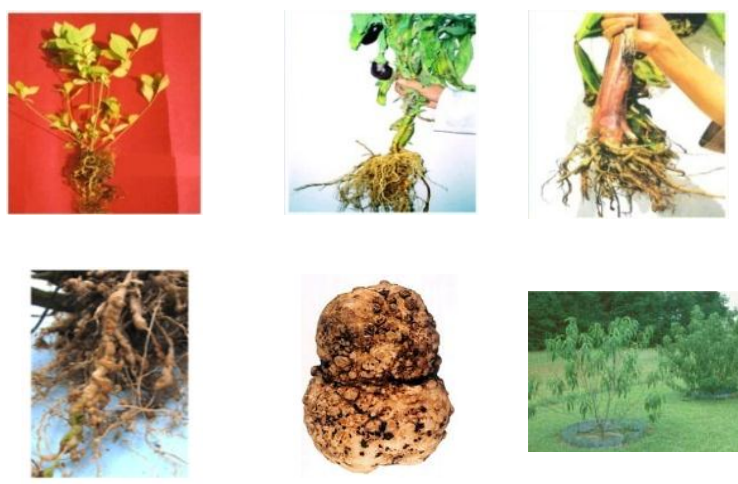

Peanut

Tomato

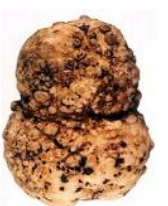

Eggplant potato
Fig (6 B): Root knot nematode symptoms in different plants

Table 2. The Distribution of different Root knot nematode different species allover Egypt.

\begin{tabular}{ccc}
\hline Governorate & Major crops in the area & Root Knot nematode genus \\
\hline Beni Suief & Tomato, cucumber, lettuce & M. incognita, M. Javanica \\
\hline Al Gharbya & $\begin{array}{c}\text { Banana, Grape, Apple, vegetables, Israeli } \\
\text { Banana }\end{array}$ & $\begin{array}{c}\text { M. Javanica } \\
\text { M.arenaria }\end{array}$ \\
\hline Al Qaliubya & Tomato, cucumber, squash & M. incognita \\
\hline AL BUHEIRA & $\begin{array}{c}\text { Cucumber, Peach, Tomato, Eggplant, } \\
\text { Beans }\end{array}$ & $\begin{array}{c}\text { M. incognita, M. Javanica, M. arenaria, } \\
\text { M.hapla }\end{array}$ \\
\hline SUHAG & $\begin{array}{c}\text { Grape,Cucumber, Tomato, Banana, } \\
\text { Horticultural Crops, banana }\end{array}$ & M. Javanica \\
\hline ASSUIT & Pomegranate, Banana, Eggplant, Tomato & M. incognita, M. Javanica \\
\hline Al Minya & Okra, Eggplant, banana, tomato & M. incognita \\
\hline Al Sharqya & Eggplant, Tomato, Cucumber & M. incognita, M. Javanica \\
\hline Al Ismailia & Tomato, Black nightshade & M. incognita \\
\hline Al Monofya & Grape & M. incognita, M. Javanica
\end{tabular}

\section{A isolation for Root Knot Nematode molecular} identification:

\section{Step: ITS Test:}

After the measurement of all obtained pure DNA from each isolate of root knot nematode, the first test (ITS) was conducted for each isolate separately to insure that the entire DNA is for root knot nematode. So, primer 5368 and 5367 were used for amplification of the ITS region, all the root knot isolates from different governorates and districts gave one main product of approximately $760 \mathrm{bp}$. This $760 \mathrm{bp} \mathrm{PCR}$ product obtained from the amplified ITS region of Meloidogyne was shorter than the product reported for other nematodes (Vrain et al., 1992; Zijlestra et al.,1997).(Fig. 7)

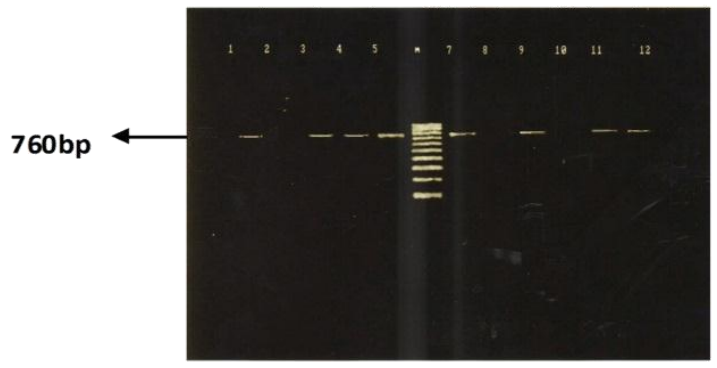

Fig (7): Typical amplification of760bp polymerase chain reaction - PCR product from template of total DNA extracted from Meloidogyne spp. of different isolates from different governorates and districts with internal transcribed spacer (ITS) with primers 5367 and 5368.

\section{Step 2: Multiplex Test:}

Sequencing data reveal that the sizes of the cloned amplified ITS regions of M. incognita is $760 \mathrm{bp}$. First, PCR reactions were performed with $\mathrm{HC} \mathrm{FI}-285$ and one of the three forward primers. The sizes of the fragments obtained after amplification could be estimated from the sequences.

The combination of primers H-18S and HCFI - 28S resulted in amplified fragment of $660 \mathrm{bp}$. this fragment is typical for M. hapla. No reaction with any other governorates isolates was shown the amplified fragment of 660bp was recognized. PCR with primers ITS and HCFI - 28S resulted in amplification of a 415 bp fragment when M. incognita was used as template. The majority from all governorates isolates react with this combination of the primers. (Fig. 8) 


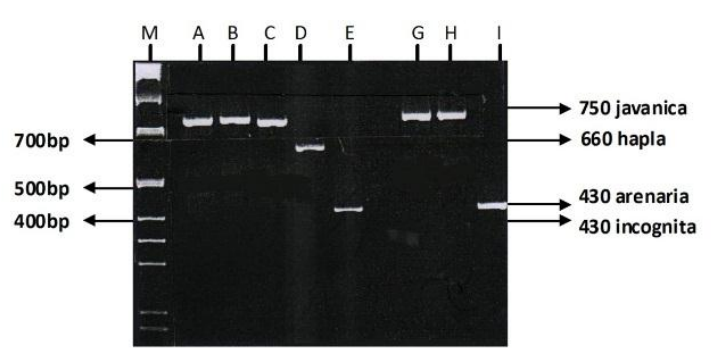

Fig (8): Amplification products of multiplex PCR. reactions using forward primers $\mathrm{H}-18 \mathrm{~S}, \mathrm{I}-\mathrm{ITS}, \mathrm{EF}$ - ITS and the reverse primer in a single PCR. reaction with $3 \mathrm{ng}$ of template DNA of root knot nematode population collected from different governorate of Egypt, when ITS primer sets H18S/HCFI-28C used with $M$. hapla the result was 660bp, when ITS Prime sets I-ITS/HCFI-28S used with M.incognita the result was $415 \mathrm{bp}$, and when ITS Prime sets H-18S/CF-ITS/HCFI-28S used with M.javanica the result was $750 \mathrm{bp}$ and when ITS primer sets ITS / HCF1, 28C used inarenaria

ITS regions of all isolates were digested with restriction enzymes. When Hind III was used in RFLP test (Restriction fragment length polymorphisms), the size of the DNA fragment obtained was not clear while 520, 200 bp bands were cleared when EcoRl are used with isolates from M.incognita and M.javanica, also two bands were recognized at $440 \mathrm{bp}$ and $320 \mathrm{bp}$ when Hind I was used with isolates from the same nematodes species. These results were typical for $M$. incognita, and M.javanica confirming the previous findings by Zijlstra et al., (1995 and 1997). (Fig. 9)

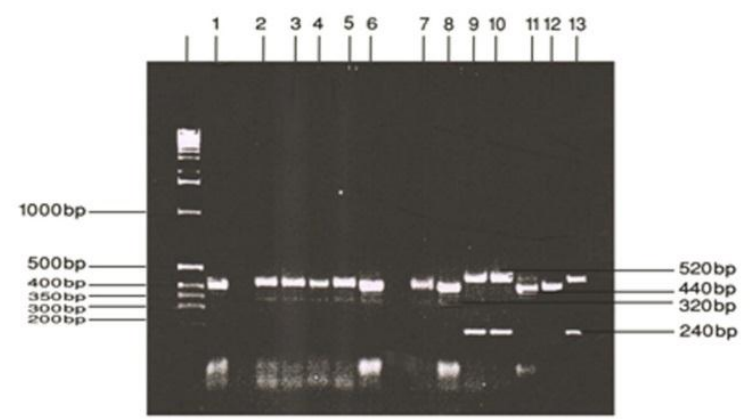

Fig (9) Restriction product OF 760 bp polymerase chain reaction amplified internal transcribed region of Meloidogyne spp upon restriction with Hind I, EcoRl

\section{Discussion and Conclusion:}

This research confirms that Root-knot nematode (Meloidogyne spp.) is the major pests in Egypt, causing yield losses to many economic crops table . There are many research opportunities in basic nematology that utilize the new approaches and tools of molecular biology. The tools will facilitate research on previously intractable questions in nematode biology; also current nematode control options include the use of nematicides, cultural practices, resistant cultivars, and crop rotations. In the future, successful integrated nematode management will depend on combinations of control tactics to reduce nematode numbers. Application of biotechnology to nematode control tactics will influence applied nematology in diverse ways, from nematode identification to the development of resistant cultivars, and will improve effectiveness and increase the number of management options available. Increased communication and cooperation between researchers with expertise in applied science is necessary to enlarge our understanding of nematode biology and ecology. The outcome will enhance development of new nematode management strategies and allow refinement of old technique.

\section{Literature Cited}

1- Zijlstra, C.; A.;E.M Levar, B.J. Uenk and C.H. Van Silfhaut, (1995). Differences between ITS region of isolates of root-knot nematodes Meloidogyne hapla and M. chitwoodi. Phytopathology 85(10); 12311237.

2- - Zijlstra, C., (1997). A fast PCR assay to identify Meloidogyne hapla, M. chitwoodi and M. fallax and to sensitively differentiate them from each other and from M. incognita in mixtures. Fundam. Appl. Nematol. 20(5): 505-511.

3- Vrain, T.c.; D.A. Wakarchuk; C.A. Levesque and R.1. Hamilton, \{1992) Intraspecific rDNA restriction fragment length polymorphism in the Xiphinema americnum. Fundam. Appl. Nmatol. 15:365-573.

4- Vrain, T.C.; (1993). Restriction fragment length polymerphism separates specific of the Xiphinema americnum group. J. Nematol. 25:361-364.

5- Ferris, V.P.; J.M. Ferris and J. Faghihi, (1994). Variation in spacer ribosomal DNA in some cystforming species of plant parasitic nematodes. Fundam. App. Nematol. 16(2): 177-184.

6- Haroon S.A. , Huettel R. and Abdel Araf Abdel Baki.(1993). An in vitro test for temperature sensitivity and resistance to Meloidogyne incognita in tomato. Journal of Nematology 25(1) : 8388,U.S.A. 